The submitted manuscript has been authorized by a

contractor of the U.S. Govemment under contract No.

DE-AC05-960R22464. Accordingly, the U.S.

Government retains a non-exclusive, royalty-free

license to publish or reproduce the published form of

this contribution, or allow others to do so, for U.S.
Government purposes."

\title{
A New User-friendly Model to Reduce Cost for Headwater Benefits Assessment
}

\author{
Yixing S. Bao ${ }^{1}$, Michael J. Sale', Robert D. Perlack ${ }^{2}$, Vedula Sarma ${ }^{3}$, \\ and Charles K. Cover ${ }^{3}$
}

\section{Abstract}

Headwater benefits at a downstream hydropower project are energy gains that are derived from the installation of upstream reservoirs. The Federal Energy Regulatory Commission is required by law to assess charges of such energy gains to downstream owners of non-federal hydropower projects. The high costs of determining headwater benefits prohibit the use of a complicated model in basins where the magnitude of the benefits is expected to be small. This paper presents a new user-friendly computer model, EFDAM (Enhanced Flow Duration Analysis Method), that not only improves the accuracy of the standard flow duration method but also reduces costs for determining headwater benefits. The EFDAM model includes a MS Windows-based interface module to provide tools for automating input data file preparation, linking and executing of a generic program, editing/viewing of input/output files, and application guidance. The EFDAM was applied to various river basins. An example was given to illustrate the main features of EFDAM application for creating input files and assessing headwater benefits at the Tulloch Hydropower Plant on the Stanislaus River Basin, California.

\section{Introduction}

Headwater benefits at a downstream project are defined as the additional power generation (i.e., energy gains) that results from regulation of the streamflow by the headwater improvement (usually a storage reservoir). Although the amount of water within the river basin does not change, the presence of the headwater improvement has the effect of moderating streamflow, reducing occurrences of spills during high-flow conditions, and providing for more water during low-flow conditions. The Code of

\footnotetext{
Environmental Sciences Division, Oak Ridge National Laboratory, Oak Ridge, TN 37831-6036

Energy Division, Oak Ridge National Laboratory, Oak Ridge, TN 37831-6036

3

Office of Hydropower Licensing, Federal Energy Regulatory Commission, Washington, D.C. 20426
} 


\section{DISCLAIMER}

This report was prepared as an account of work sponsored by an agency of the United States Government. Neither the United States Government nor any agency thereof, nor any of their employees, make any warranty, express or implied, or assumes any legal liability or responsibility for the accuracy, completeness, or usefulness of any information, apparatus, product, or process disclosed, or represents that its use would not infringe privately owned rights. Reference herein to any specific commercial product, process, or service by trade name, trademark, manufacturer, or otherwise does not necessarily constitute or imply its endorsement, recommendation, or favoring by the United States Government or any agency thereof. The views and opinions of authors expressed herein do not necessarily state or reflect those of the United States Government or any agency thereof. 


\section{DISCLAIMER}

Portions of this document may be illegible in electronic image products. Images are produced from the best available original document. 
Federal Regulations (Code of Federal Regulations, 1994) requires that the Headwater Benefits Energy Gains (HWBEG) model (FERC 1993) be used to calculate energy gains, except for headwater benefits determinations that are not complex, or in which the headwater benefits are expected to be low. The high cost of determining headwater benefits prohibits the use of a complicated model in basins where the magnitude of the benefits is expected to be small.

Flow-duration analysis is an accepted straightforward method for investigating numerous water-resource engineering problems (Vogel and Fennessey 1995). To assess headwater benefits at a downstream site, a flow-duration curve is constructed by arranging each flow recording (usually a daily flow reading) in decreasing order of magnitude rather than in chronological sequence. A flow-duration curve shows the percentage of time a given flow is equaled or exceeded (percent exceedance) during a specified period of time. The percent exceedance for a given flow is calculated using a plotting position formula based on the rank of flow and total number of flow data points. The impact on the headwater improvement from flow regulation is determined by comparing flow-duration curves before and after operation of the headwater project. The flow contributing to energy gains is the difference in areas under the before and after flow-duration curves bounded by the turbine flow range. This contributing flow multiplied by a power-to-flow constant or function yields the gross energy gain.

The main purposes of this paper are to present a generic computer program for the FDA method and to simplify the application of the model. Motivation for this study was to provide a simple and user-friendly tool that hydropower licensees (i.e., downstream beneficiaries) could use to assess headwater benefits.

\section{Overview of Enhanced Flow Duration Analysis Method}

We evaluated the accuracy and appropriateness of FERC's standard flowduration analysis and concluded that the FDA method is an appropriate method to determine energy gains in river basins that have few upstream reservoirs or do not involve a high degree of streamflow regulation (Bao et al. 1997). We also improved the standard FDA method by replacing a constant power-to-turbine-flow ratio with variable stage-flow and efficiency-flow relationships and by expanding the model's capability to derive unregulated flows based on regulated flow and reservoir storage changes.

If the conversion efficiency from water to power is assumed to remain constant within the turbine flow range, the difference in area between the before and after curves would be equivalent to the energy gains as follows:

$$
E_{g}=P F R \int_{Q_{t \min }}^{Q_{\text {max }}}\left(F_{a}-F_{b}\right) d q
$$


where $E_{\mathrm{g}}$ is the gross energy gains for the period under consideration $(\mathrm{kW}) ; Q_{t \max }$ and $Q_{t \text { min }}$ are maximum and minimum turbine flow capacities (cfs); $F_{b}$ and $F_{a}$ are exceedance probabilities before and after the installation of headwater projects; $q$ is flow (cfs); and $P F R$ is a constant power-to-flow ratio (kW/cfs).

The enhanced FDA method incorporates a variable flow-hydraulic head relationship and turbine flow-power generation efficiency curve in calculation of power generation and hence energy gains. The basic water power equation is as follows:

$$
P=e \cdot \frac{q \cdot H}{11.8}
$$

where $P$ is power (kW); $e$ is the combined turbine and generator efficiency; $H$ is the net hydraulic head (ft); and $q$ is flow (cfs).

The efficiency is a function of turbine inflow, $e=e(q)$. Hydraulic head, $H$, is related to flow in the stage-discharge relationship $H=H(q)$. Combining the efficiency curve and stage-flow rating curve, the power generation can be derived as a function of flow:

$$
E_{g}=\int_{Q_{\min }}^{Q_{\max }} e(q) \frac{H(q)}{11.8}\left(F_{a}-F_{b}\right) d q
$$

The option to estimate unregulated flow data is necessary when the unregulated flow data (before installation of upstream reservoirs) are not available. We therefore modified the FDA method to derive the unregulated stream flow from the regulated flow data by adding back the storage changes as indicated in the following equation:

$$
q_{\text {in }}=q_{\text {out }}+\Delta_{s} / \Delta_{t}
$$

where $q_{\text {in }}$ is the inflow at the upstream reservoir inlet; $q_{\text {out }}$ is the outflow at the hydropower plant; and $\Delta_{s} / \Delta_{t}$ is the change of upstream reservoir storage over time period. $\Delta_{\mathrm{t}}$.

\section{Simplification of FDA Method and Model Application}

In a companion paper (Sarma, et al.1999). We demonstrate the efforts to further simplify the FDA method through a multiple-regression technique and how such simplification affects the validity of the FDA method are presented in. In that paper we concluded that further simplification of the relatively simple FDA method by a regression approach is not appropriate. Instead, the focus should be placed on the simplification of the preprocess components to make it easier for retrieving data,

Bao, et. al. 
preparing input files, and generally automating the headwater benefits assessment procedure. In fact, with the availability of powerful personal computers, the capability of the FDA method can be further enhanced (using a better, but maybe more sophisticated, algorithm) without adding more burden on users of the model. Thus, the process of simplifying the FDA method should follow two guidelines: (1) minimize the model application effort, and (2) enhance the method by incorporating better algorithms. The first guideline for making the model easier to use is to add limit the number of options that may confuse potential users. The enhanced FDA method follows the second guideline.

\section{Enhanced Flow Duration Analysis $\underline{\text { Method (EFDAM) Model }}$}

We developed two separate procedures to simplify the application of standard/enhanced FDA methods. First, we developed a computer code for the general application of both the standard and the enhanced FDA methods based on the HWBFDA model which was developed specifically for test cases (Bao et al. 1997). Selection of the standard FDA or the enhanced FDA method is determined by user input options and availability of hydropower and flow data. The generic model (EFDAM.EXE) can be executed similarly to the HWBFDA once the stream flow data and hydropower data input files are created. Second, we developed user-friendly interface routines in Visual BASIC to help the users by (1) providing application guidance and examples, (2) preparing the main input data files, (3) editing flow and hydropower data files, (4) executing the EFDAM.EXE and (5) viewing output files. Although users can run EFDAM without access to the Visual BASIC interface program (called EFDAMv1.EXE), this interface program is the key to making it much easier and simpler to use when preparing data files and running the model.

One of the key components of the EFDAM model is a computer program for both the standard and the enhanced FDA methods. This program consists of six subroutines and four functions. The logic structure of EFDAM is shown in Figure 1. The MAIN program calls a subroutine FILEIO to read input data, to initialize local and global variables and to adjust regulated and unregulated flow data (normalization). The daily flow data series are sorted into ascending numerical order using the "Heapsort algorithm" by the SORT subroutine to create a flow-duration series. The subroutine HPOWERC is called to calculate annual averaged energy gains, if the constant powerflow ratio is used. Otherwise, HPOWERV is called to calculate energy gains when a variable power-flow relationship is specified by the user. The flow statistics, such as mean, median, standard deviation, skewness, and coefficient of variation are calculated in STATS1. Results of energy gains, along with flow-duration curves and input files, are written to output files in MAIN subroutine. 


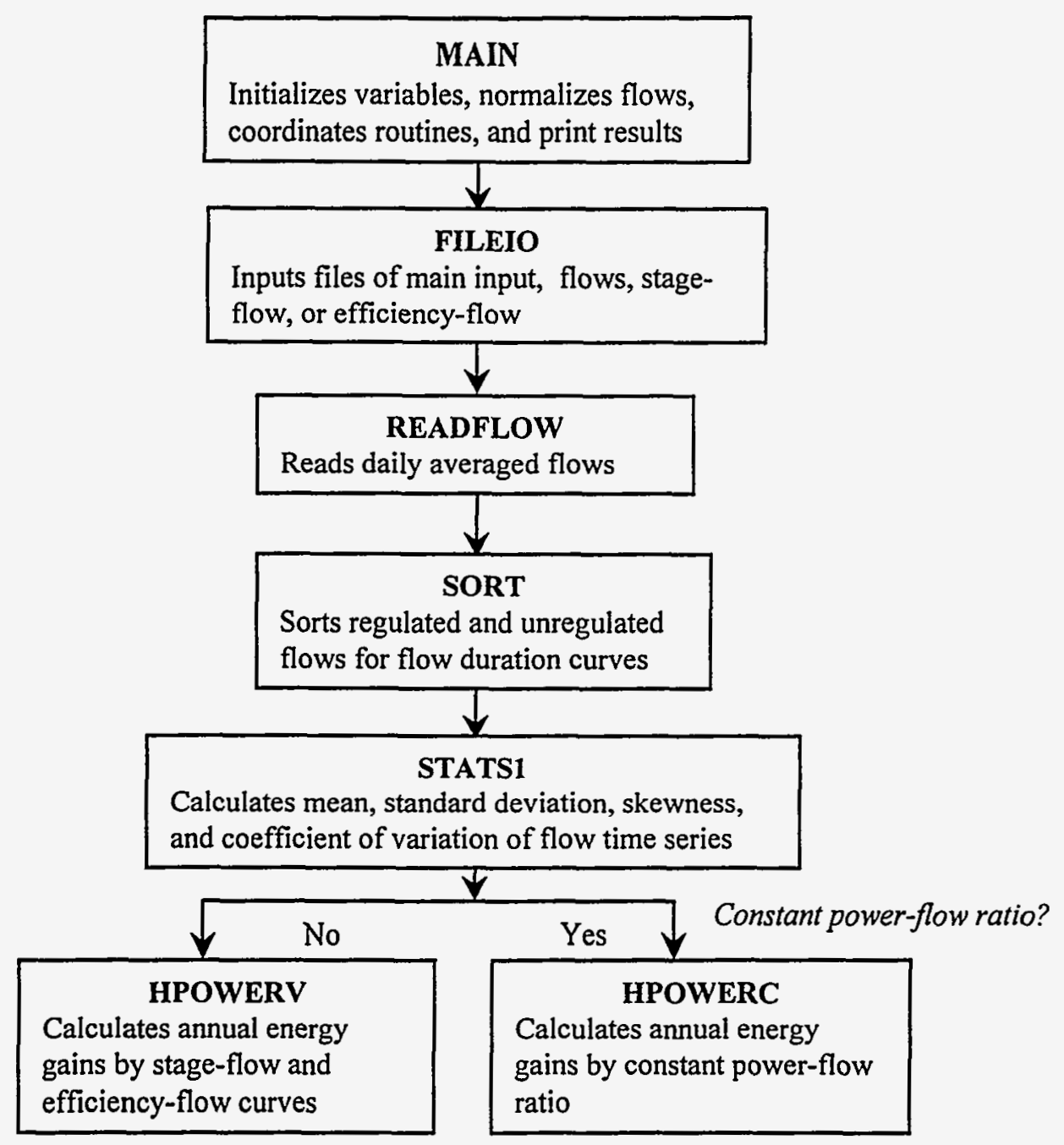

\section{Figure 1. Flowchart of EFDAM program subroutines.}

In addition to variable initialization and coordination among the subroutines, the MAIN program contains three functions that can be written into separate subroutines: flow normalization, generation of flow-duration curves, and output of results.

Determination of headwater benefits by the FDA method is based on an assumption that the annual total water volume does not change before and after the installation of upstream reservoirs. In other words, the upstream reservoirs only affect the flow pattern at the downstream hydropower plant. No net water loss or gain due to the presence of upstream reservoirs is assumed to occur. Flow normalization is used to adjust one or both of regulated and unregulated flow data series so that the averaged annual volume of water for regulated and unregulated flows are equal. Four options for flow normalization are incorporated into EFDAM.

The FILEIO subroutine reads the input file names, river basin and hydropower 
plant variables. Up to seven input files are required in EFDAM: (1) the main control file, (2) the stream flow data after installation of upstream reservoirs, (3) the stream flow data before installation of upstream reservoirs, (4) the upstream reservoir storage, (5) the power-flow curve, (6) the stage-flow curve, and (7) the flow-efficiency curve. The first two input files are required to run EFDAM. The main input file is required, which contains other input/output files names, user-supplied options, drainage areas, and turbine flow capacities. The unregulated flow (3) can be generated in EFDAM if the data on upstream reservoir storage (4) are available. If the constant power-flow ratio is used, files (5), (6), and (7) are not needed. The stage-flow curve and the flow-efficiency curve can be combined into the power-flow curve. Therefore, if the variable power-flow option is selected, either file (5) is required or files (6) and (7) are needed. EFDAM will generate three output files: (1) main output file, (2) flow-duration data points for regulated flows, and (3) flow-duration data points for unregulated flows. The main input option parameters are FLAG_B for unregulated flow, FLAG_C for power-flow ratio, and FLAG_N for flow normalization, as shown in Figure 2.

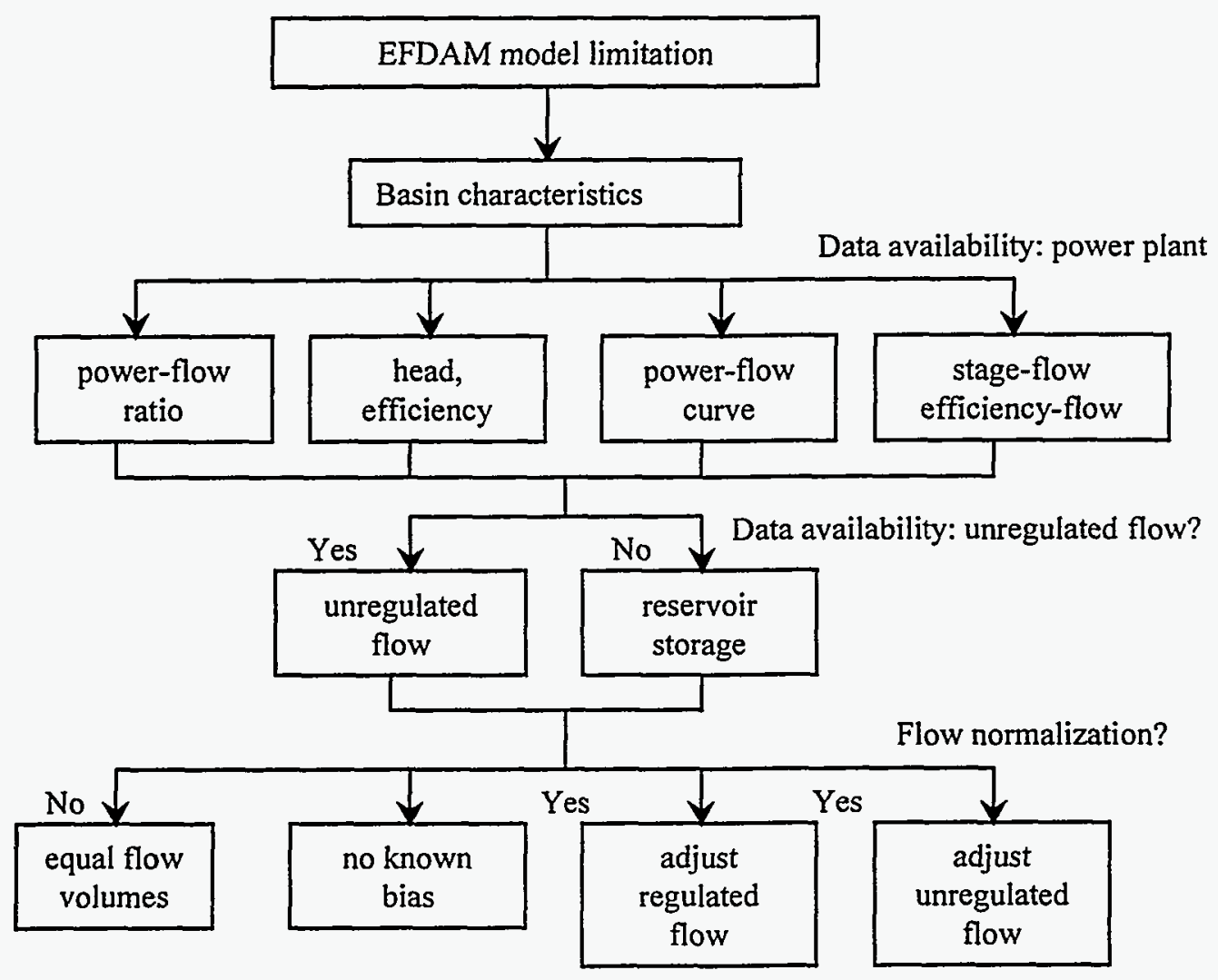

Figure 2. Summary of input options in EFDAM model.

The main purpose of the EFDAM interface (compiled as EFDAM-v1.EXE) is to simplify application of EFDAM by developing an Microsoft Windows-based, userfriendly interface for editing/viewing input/output files, linking and executing the EFDAM program, and providing application guidance. The MAIN menu allows the 
user to select/create the main input file, select the model (e.g., EFDAM), view/edit input files, view a flow duration example, run the model, and view model results. Tips for the important entries in the main menu and data input menu will automatically show when the mouse points at the entry.

\section{Example of Application}

As an example, EFDAM was used to assess energy gains at the Tulloch Hydropower Plant on the Stanislaus River Basin, California. The Stanislaus River Basin is relatively simple and consists of a single flow-regulating headwater project and three downstream hydropower projects. The first downstream project, the Tulloch Hydropower Plant, operates as a run-of-the-river facility and relies on upstream flow regulation from the Bureau of Reclamation's New Melones Headwater Project (FERC 1992). Energy gains are calculated for the Tulloch facility for the 1980 to 1991 period.

Simplifying the preparation of input data files preparation is the most important function of the EFDAM Interface. While the user enters the main input file name, entries of the output file name and flow-duration data output files are automatically filed by extracting the input file name and adding a specific extension name for each file (Figure 3). Suggested file extensions include "**out" for the main output file name extension, "**.ota" for the regulated flow-duration data file in which letter "a" stands for after the installation of upstream reservoirs, and "*.otb" for the unregulated flowduration data file in which letter "b" stands for before the installation of upstream reservoirs. These file names can be changed manually by the user.

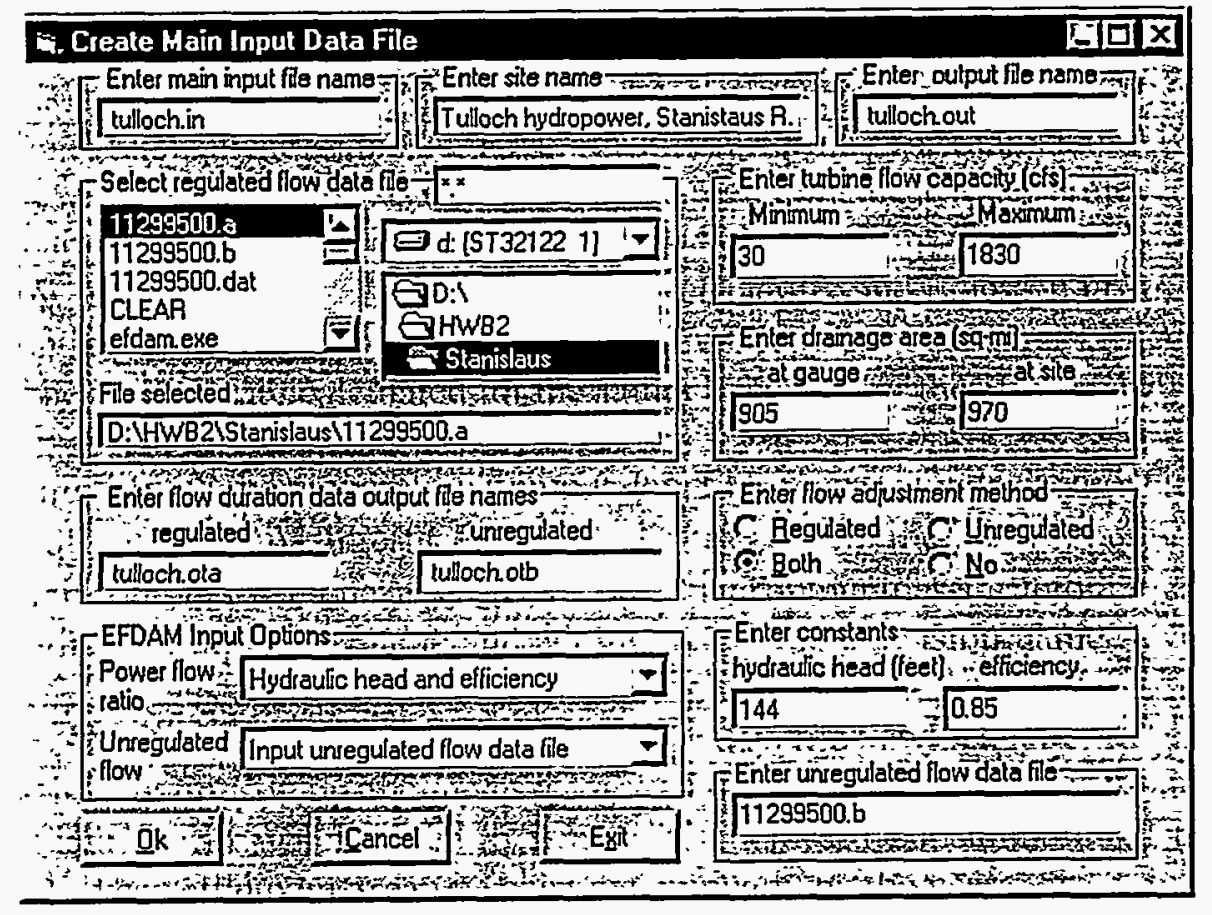

Figure 3. Using the EFDAM Interface to create the main input file: tulloch.in. 
The Interface creates a main input file of Tulloch1.in and returns to the MAIN menu with information about the working directory, main input file, and location of EFDAM model (Figure 4).

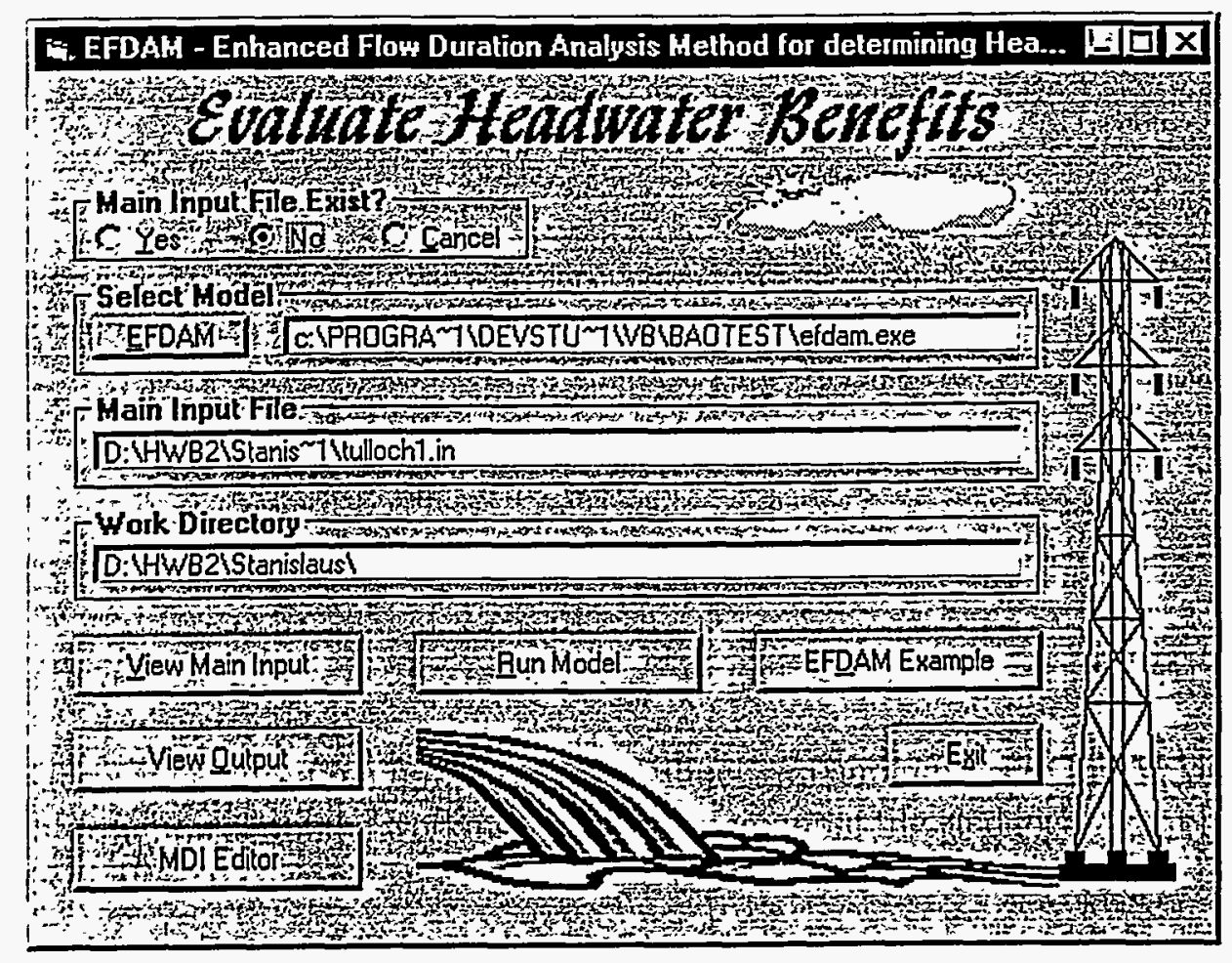

\section{Figure 4. Back to the MAIN menu of EFDAM interface after the Interface created a main input file of Tulloch1.in.}

The View Main Input button in the MAIN menu opens the main input file (Tulloch1.in) in the DOS editor for review and editing. The DOS editor is preferred because of its fixed-width font. The Run Model button launches EFDAM model in a DOS window.

The EXAMPLE menu, accessible from the MAIN menu, helps the user understand the FDA method and to show a step-by-step application. Only the schematic illustration of the FDA method is built into the menu (Figure 5). In the future, the EXAMPLE menu will include a complete, realistic step-by-step application.

The resulting annual energy gains from the Tulloch project are 15,914 $\mathrm{MWh} /$ year. The unregulated flow data are from the USGS gauge station (for the period of 1931-1967 at station ID 11299500), while the regulated flow data (for a period of 1979-1991) are from a different source-originally from the Bureau of Reclamation (FERC 1992). Because there is a $3.4 \%$ difference in an averaged daily flow between regulated $(1533 \mathrm{cfs})$ and unregulated $(1587 \mathrm{cfs})$ conditions, the default two-curve flow 
normalization was used. For comparison, we reran EFDAM.EXE with the flow normalization option set to 'No'. The corresponding annual energy gain falls to 14,180 $\mathrm{MWh} /$ year. A difference of $3.4 \%$ in the volume of water resulted in an $11 \%$ reduction in energy gains. The comparison with and without flow normalization confirms that the energy gains are sensitive to flow changes.

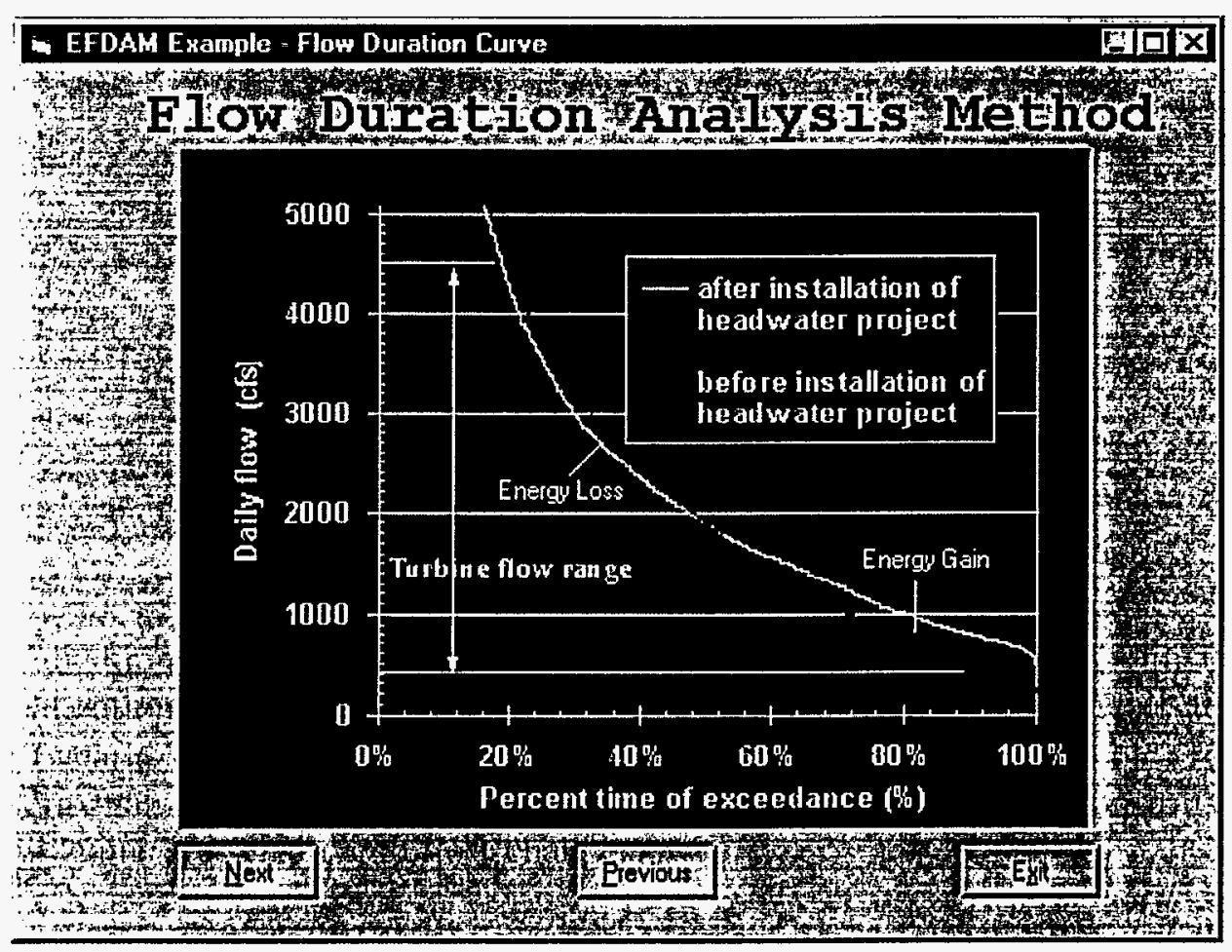

Figure 5. Example menu to show the FDA method and step-by-step application.

Finally, many easy-to-use features were developed in EFDAM. For instance, EFDAM provides a multiple document notepad (MDI) as a default. The MDI editor can open multiple files simultaneously. It is very useful to simultaneously view several input and output files and to document the model runs (e.g., project background information, notes, important input parameters, and discussion of results).

\section{Conclusions}

In this study, we developed a computer model, EFDAM, to automate and simplify the application of the standard and enhanced FDA methods for determining headwater benefits. A separate Microsoft Windows-based, user-friendly, interface module was developed to help the user by (1) providing application guidance and examples, (2) preparing the main input data file, (3) editing flow and hydropower data files, (4) executing the EFDAM.EXE, and (5) viewing output files. The EFDAM and its interface module significantly improved the accuracy of the FDA method and also 
reduced the application costs by automating data input preparation and execution. EFDAM further improved the FDA method by adding more options to expand capabilities while maintaining its easy of use.

One of the major disadvantages preventing the use of a more complex HWBEG model (FERC 1993) is the time consuming of preparing data files. The user-friendly interface in EFDAM can also be applied to HWBEG to dramatically simplify the data preparation process and reduce the assessment costs. We recommend expanding the interface module to include the HWBEG model, which will significantly simplify the application process of HWBEG and provide a suite of simple and detailed models.

\section{Acknowledgments}

We thank Dr. Glenn Cada and Henriette Jager for their review of this paper. The research was sponsored by the Office of Hydropower Licensing, Federal Energy Regulatory Commission and U.S. Department of Energy, under contract number DEAC05-96OR22464 with Lockheed Martin Energy Research Corp. This is Publication No. 4869 , Environmental Sciences Division, ORNL.

\section{References}

Bao, Y.S., R.D. Perlack, M.J. Sale, Alternative Methods to Determine Headwater Benefits, Oak Ridge National Laboratory, ORNL/TM-13496, Prepared for the Federal Energy Regulatory Commission, Oak Ridge, Tennessee, November 1997.

Code of Federal Regulations (CFR), Title 18, April 1, 1994.

Federal Energy Regulatory Commission(FERC), Determination of Headwater Benefits: Stanislaus River Basin, Division of Project Compliance and Administration, OHL Docket No. HB43-91-1-000, Washington D.C., August 1992.

Federal Energy Regulatory Commission (FERC), The Microcomputer Fortran Version of the Headwater Benefits Energy (HWBEG) Gains Model, Division of Project Compliance and Administration, Washington D.C., June 1993.

Sarma, V.Y., C.K. Cover, and Y. Bao, "Headwater Benefits Methodology Simplification", WaterPower 99, July 1999.

Vogel, R. M. And N. M. Fennessey, "Flow Duration Curves II: A Review of Applications in Water Resources Planning," Water Resources Bulletin, 31(6):1029-1039, December, 1995. 